\title{
Supply of corneal tissue in the United Kingdom
}

Within the last seven years in the UK there have been significant changes in the supply of corneal tissue for transplantation. Most ophthalmic surgeons here previously relied on local donors as their only source of tissue for corneal grafts. This meant that the grafts often had to be performed as emergency operations, and that excess tissue was wasted because of limited storage times and the lack of a simple routine mechanism for transferring the tissue to other hospitals. The likelihood of tissue matching for patients at high risk of immunological rejection was also severely limited. Some hospitals, notably Moorfields Eye Hospital in London and the Queen Victoria Hospital in East Grinstead, were able to schedule grafts by ensuring an adequate supply of tissue through well organised donor retrieval programmes and through the establishment of eye banks, but they were very much in the minority. The eye banks at East Grinstead and Moorfields were set up in 1959 and 1965, respectively.

\section{Corneal Transplant Service}

In 1983 the Corneal Transplant Service was inaugurated by the UK Transplant Service (UKTS) and the Iris Fund for the Prevention of Blindness with the aims of improving the availability of corneal tissue for transplantation and of reducing tissue wastage. ' The functions of UKTS are to match and distribute organs and tissues for transplantation, to hold lists of patients awaiting transplants throughout the UK, to provide laboratory services for tissue typing including the supply of tissue typing reagents to all tissue typing laboratories in the UK, and to collect and analyse statistical data on transplantation in the UK. The Corneal Transplant Subcommittee of the UKTS Management Committee was established by the Department of Health to advise on the functioning of this new service to ophthalmologists.

The Corneal Transplant Service enables corneas that cannot be used locally to be offered through the UKTS for use in patients at other hospitals, ensuring a wide and fair distribution of tissue and greatly reducing wastage. The UKTS makes all of the necessary arrangements, including transportation, and relieves surgeons of the administrative burden involved in sharing tissue. In addition patients who are likely to suffer graft failure through immunological rejection have a far greater chance of receiving a well matched cornea, because links with other transplant teams through UKTS and Transplant Co-ordinators have increased the numbers of corneas retrieved from tissue typed multiorgan donors. Corneas from tissue typed donors are offered for patients on the national waiting list with the best tissue match.

\section{Corneal Tissue Act 1986}

Under the Human Tissues Act 1961 organs and tissues for transplantation could be removed from a donor only by a fully registered medical practitioner. There was always a chance, therefore, that eyes would not be retrieved from a donor by an ophthalmologist because of other more pressing clinical demands. In 1986 this law was amended to allow suitably trained persons who were not medically qualified to remove eyes for therapeutic, research, and teaching purposes.
A course, organised by the Department of Ophthalmology in Bristol, is run specifically as a result of this Act to provide training in enucleation and storage techniques. The Corneal Tissue Act 1986 has thus reduced the likelihood of eyes not being retrieved and has brought the UK into line with other European countries and the USA. Indeed, hospitals, such as in Norwich, that have specifically employed someone to retrieve eyes have been able markedly to increase the amount of tissue collected.

\section{Corneal Transplant Service Eye Bank}

The next major advance in the supply of corneal tissue in the UK also came in 1986 when the Corneal Transplant Service Eye Bank was set up in Bristol. ${ }^{2}$ This was a joint initiative by Bristol University Department of Ophthalmology, the UKTS, and the Iris Fund. This eye bank, which is situated in the theatre suite of the Bristol Eye Hospital, was the first in the UK to apply organ culture techniques for the storage of human corneas for transplantation. ${ }^{3}$ Instead of storing whole eyes in moist chambers at $4^{\circ} \mathrm{C}$ or corneoscleral discs in tissue culture medium at $4^{\circ} \mathrm{C}$, corneas are excised with a $2-4 \mathrm{~mm}$ scleral rim and suspended in tissue culture medium at $34^{\circ} \mathrm{C}$, which extends the permissible storage time from a few hours or days to 30 days. ${ }^{46}$

When coupled with the national distribution service provided by the UKTS this capacity for extended corneal storage has a number of advantages. Perhaps the most important is that the timing of a routine graft need no longer be determined by the immediate availability of a suitable local donor, allowing grafts to be performed electively. Surgeons are now able to plan grafts well in advance simply by requesting corneas through the UKTS for the dates when they wish to graft their patients. Over $50 \%$ of grafts are scheduled with seven or more days' notice and $25 \%$ are planned more than two weeks in advance. Only $10 \%$ of grafts are performed within two days of requests being placed with the UKTS, and these are mainly emergencies. The average time between a request and the graft is 11 days, which is ample time both for the surgeons and the patients to make all necessary arrangements. Moreover only $13 \%$ of organ cultured corneas are grafted in evenings after $6 \mathrm{pm}$. Another major advantage is that corneas are always available for emergencies. The longer storage time also means that essential tasks such as donor screening for HIV and hepatitis B do not need to be done with such urgency but can be carried out at the convenience of the testing laboratory.

During organ culture, corneas are screened for bacterial and fungal contamination. At least $40 \%$ of the eyes sent to the eye bank are contaminated by bacteria (mainly Staphylococcus spp). Cleaning of the external ocular surface with polyvinylpyrrolidone iodine before corneoscleral disc excision and the antibiotics in the culture medium reduce the incidence of contamination during organ culture to only $7 \%$. Contamination is revealed either through clouding of the culture medium or by routine screening of the medium during culture. All contaminated organ cultures are discarded. Thus surgeons receive tissue that should be free of bacterial and fungal contaminants, which is not the case with corneas or whole eyes stored at $4^{\circ} \mathrm{C}$. 


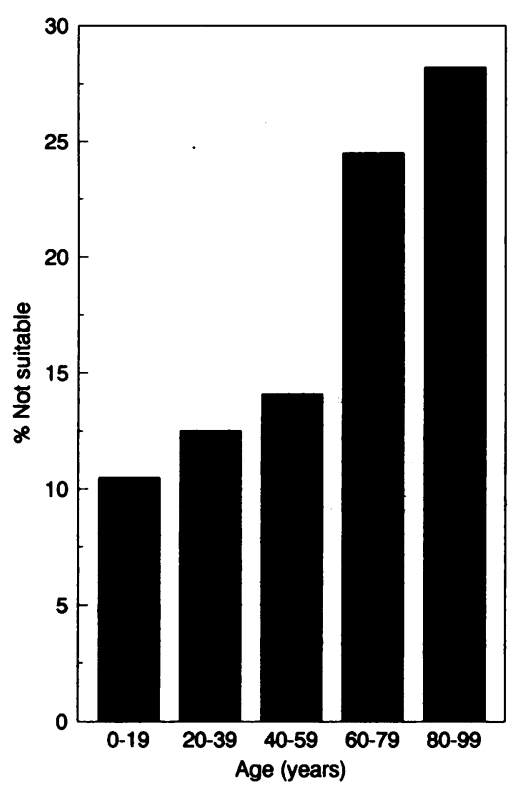

Figure 1 The influence of donor age on the proportion of organ cultured corneas discarded because of endothelial defects between 1 fanuary 1989 and 30 fune 1990. The total numbers of organ cultured corneas in each age range were: $0-19$ yr, 380; 20-39 $y r, 530 ; 40-59 y r, 810$ 60-79yr, 1365; 80-99yr, 341 .

The corneal endothelium is carefully examined prior to transplantation to ensure an intact endothelial mosaic with an adequate density of viable cells. This allows corneas from older donors to be used with confidence and damaged corneas from younger donors that might otherwise have been used can be identified and discarded. As might be expected, the discard rate owing to endothelial defects increases with donor age, rising from approximately $10 \%$ in donors under 20 years to almost $30 \%$ in donors over 80 years (Fig 1). Overall, approximately $30 \%$ of corneas stored in organ culture are eventually discarded for a variety of reasons including inadequate endothelium, cause of donor's death, microbial contamination, and lack of HIV or hepatitis B tests (Fig 2).

In 1986 a total of 59 organ cultured corneas were supplied through the Bristol eye bank to 11 hospitals. Since then there has been a substantial rise both in the numbers of corneas stored and distributed and in the number of participating hospitals. Within three years over 1500 corneas a year were being supplied through the Bristol eye bank to over 100 hospitals throughout the UK and Eire (Fig 3). The average donor age between 1 January 1989 and 30 June 1990 was 53 years (SD 22.9, $\mathrm{n}=1802$ ) and that of tissue typed donors was 37 years (SD 16.6, $n=469$ ) (Fig 4). During this period $26 \%$ of eye donors were tissue typed, and $80 \%$ of those tissue typed corneas were grafted into tissue matched recipients. Overall, the Bristol eye bank has supplied almost 4000 corneas for transplants in its first four years of operation.

One of the main factors in the success of this service has been the co-operation between the UKTS and the eye banks at Moorfields and East Grinstead, which use $4^{\circ} \mathrm{C}$ storage

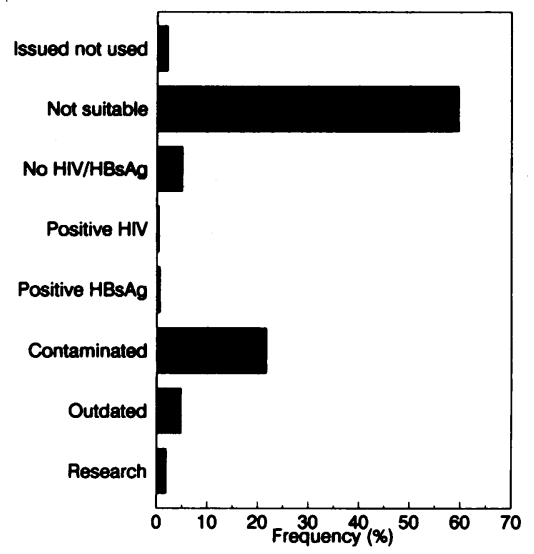

Figure 2 Discarded corneas between 1 fanuary 1989 and $30 \mathrm{fune} 1990$. A total of 1083 comeas were discarded out of 3426 stored $(32 \%)$. The category 'Not suitable' includes cormeas rejected because either the donor's cause of death was a contraindication for transplantation or the endothelium was unsuitable for transplantation.

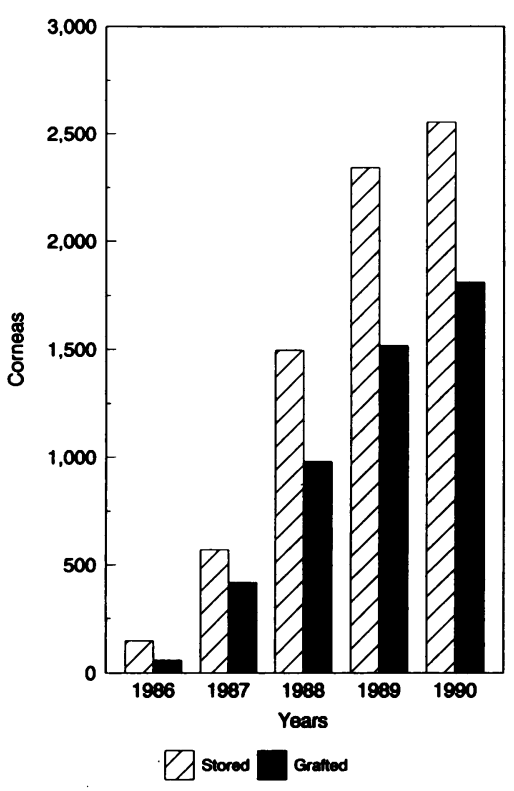

Figure 3 Corneas stored in the CTS Eye Bank in Bristol and supplied for transplantation between 1 Fanuary 1989 and 30 fune 1990. The data for 1990 are extrapolated from the figures for the first six months of that year.

techniques, since excess tissue collected in the areas served by those banks can be channelled through Bristol for redistribution to other hospitals in the UK. This can be done without undue haste owing to the greater amount of time that the tissue can be stored in a viable state in organ culture. There has also been a tremendous willingness of surgeons in other hospitals to retrieve eyes not required for their own immediate needs.

\section{Corneal transplant service eye bank network}

In 1988 the David Lucas Eye Bank was opened in Manchester. This facility also stores corneas by organ culture and is fully integrated within the Corneal Transplant Service. The pattern in the UK has thus shifted from corneas being procured and used locally to the majority of corneal tissue being supplied through a loose network of four eye banks situated at Bristol, East Grinstead, Manchester, and Moorfields. In 1989 alone, over 2000 corneas were supplied for grafts through these four eye banks. This system has the advantage that just a few eye banks serve a wide geographical area in an efficient and cost effective manner. Surgeons throughout the UK are offered the widest possible choice of corneal tissue for their patients, and special needs such as for

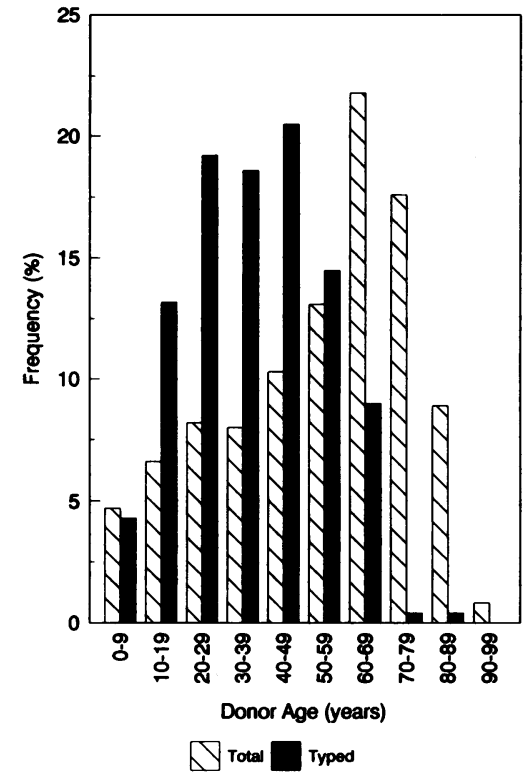

Figure 4 Age distributions of all donors $(n=1802)$ and of tissuetyped donors $(n=469)$ of eyes received by the CTS Eye Bank in Bristol between 1 fanuary 1989 and 30 fune 1990. 
tissue matched corneas or for corneas from young or infant donors are far more likely to be satisfied. It would seem pointless to promote numerous small eye banks each serving a small population, since this would greatly increase the unit costs of storing corneas, reduce the choice of tissue for the local surgeons, and greatly complicate the logistics of sharing corneas. At present cost of storing a cornea at Bristol is approximately $£ 70$. This figure is based on the annual cost of staff, consumables, and services divided by the number of corneas supplied for grafts. Such a low figure is achieved solely because of the large number of corneas supplied namely, about 2000 a year.

It would not be appropriate for every eye bank to use organ culture as the storage method of choice. Indeed this could be detrimental in that it would reduce flexibility of the eye bank network in the UK. It is quite clear that many eye banks require only short-term $4^{\circ} \mathrm{C}$ storage to function, as demonstrated by the Moorfields eye bank and the highly successful eye banks in the USA. To achieve the wide national distribution of corneas in an efficient and calm manner, however, the extended storage period offered by organ culture is of immense value.

The organ culture technique was developed in Minneapolis in the early $1970 \mathrm{~s}^{45}$ but is little used in the USA. Organ culture has, however, been used for a number of years in the eye banks in Arhus, Amsterdam, Vienna, and Hamburg, allowing these few eye banks to serve the needs of wide geographical areas. This applies especially to the eye banks at Arhus and at Amsterdam, the latter being closely associated with Eurotransplant, which provides similar organ matching and distribution services to the UKTS for the Benelux countries, West Germany, and Austria. To promote eye banking within Europe, the European Association of Eye Banks was inaugurated in 1989 at a meeting arranged by Professor Neils Ehlers in Arhus. The exchange of tissue typed corneas within Europe via national distribution services such as the UKTS and Eurotransplant has already been instituted.

\section{Corneal transplant follow-up study}

The data collection potential of the UKTS has been utilised for the analysis of corneal transplant follow-up data. The Corneal Transplant Study was set up to collect data on a UK national basis to investigate the influences of tissue matching, as well as clinical, surgical, and constitutional factors on graft survival.' The data will be analysed by multifactorial methods developed for the analysis of renal transplant data ${ }^{8}$ that take into account interrelationships between the various factors. The statistical methods allow the simultaneous estimation of effects on graft survival, distinguish between acute and chronic influences, and make provision for unrecorded aspects of centre individuality. This study will provide an assessment of the efficacy of organ culture for corneal storage compared with $4^{\circ} \mathrm{C}$ storage methods.
Future prospects

The McCarey-Kaufman medium for the storage of corneoscleral discs at $4^{\circ} \mathrm{C}$ was devised in $1974 .{ }^{9}$ Recently there has been renewed interest in this area, and a number of new solutions have been proposed, ${ }^{10}$ though none has yet been able to provide the 30 days of storage permissible with organ culture. The advantages of storage at $4^{\circ} \mathrm{C}$ are purportedly simplicity and low cost, though when applied on a large scale with adequate facilities and expertise organ culture is also straightforward and inexpensive.

Cryopreservation at $-196^{\circ} \mathrm{C}$ has the potential for providing virtually indefinite storage, ${ }^{12}$ though a reliable technique for the cryopreservation of corneas has yet to be developed. ${ }^{313}$ Should such a technique become available, eye banks would have at their disposal a complete range of short, medium, and long term techniques for storing viable corneas. Cryopreservation would perhaps be most useful for storing excess corneas and corneas from tissue typed donors that have no matched recipients. Moreover, cryopreservation offers the prospect of a bank of tissue for use in major disasters anywhere in the world.

We thank the following for their generous and continuing support of the Corneal Transplant Service: Mrs Susanna Burr, Iris Fund for the Prevention of Blindness; Col S Gaussen and Mrs Christine Wilkins, National Eye Research Centre; Mr Paul Bowerman, Bristol CTS Eye Bank; Mr T Casey, Queen Victoria Hospital, East Grinstead; Mr A Steele and Mrs S Ritten, Moorfields Eye Hospital; Mr A Ridgway and $\mathrm{Mr}$ Borys Marcyniuk, Manchester Royal Eye Hospital; members of the and Mr Borys Marcyniuk, Manchester Royal Eye Hospital, members of the Committee; and Rotary Club Districts 110 and 120.

W J ARMITAGE S J MOSS

Department of Ophthalmology, D LEASTY

University of Bristol,

Lower Maudlin Street,

Bristol BS1 2LX

UK Transplant Service,

B A BRADLEY

Southmead Road, Bristol BS10 5ND

1 Bradley BA. Corneal supply in the United Kingdom. Trans Ophthalmol Soc UK 1986; 105: 397-400.

2 Easty DL, Carter CA, Lewkowicz-Moss SJ. Corneal cell culture and organ storage. Trans Ophthalmol Soc UK 1986; 105: 385-96.

3 Armitage WJ, Moss SJ. Storage of corneas for transplantation. In: Easty DL, ed. Current ophthalmic surgery. London: Baillière Tindall, 1990.

4 Summerlin WT, Miller GE, Harris JE, Good RA. The organ-cultured cornea: an in vitro study. Invest Ophthalmol Vis Sci 1973; 12: 176-80.

5 Doughman DJ, Harris JE, Schmitt MK. Penetrating keratoplasty using $37^{\circ} \mathrm{C}$ organ cultured cornea. Ophthalmology 1976; 81: 778-93.

6 Pels E, Schuchard Y. Organ-culture preservation of human corneas. Doc Ophthalmol 1983; 56: 147-53.

7 Easty DL, Rogers CA, Gore SM, Bradley BA, Karwatowski WS. Corneal Transplant Follow-up Study (CTFS). Invest Ophthalmol Vis Sci 1990; 31: 270.

8 Gilks WR, Bradley BA, Gore SM, Selwood NH. Immunogenetic and clinical factors affecting renal transplantation - a rigorous analysis of data recorded by the UK Transplant Service. Transplantation 1986; 42: 39-45.

9 McCarey BE, Kaufmann HE. Improved corneal storage. Invest Ophthalmol Vis Sci 1974; 13: 165-73.

10 Lindstrom RL, Skelnik DL, Lass J, et al. Optisol - a new $4^{\circ} \mathrm{C}$ corneal preservation solution. Invest Ophthalmol Vis Sci 1990; 31: 475.

11 Laing RA, Hirokawa K, Yang ZR, Oak S. Maintenance of corneal endothelium in storage media. Invest Ophthalmol Vis Sci 1990; 31: 268.

12 Armitage WJ. Cryopreservation of animal cells. In: Bowler K, Fuller BJ, eds. Temperature and animal cells. Society for Experimental Biology Symposium No. 41. Cambridge: Company of Biologists, 1987: 379-93.

13 Taylor MJ. Clinical cryobiology of tissues: preservation of corneas. Cryobiology 1986; 23: 323-53. 